\title{
Polyvinylidene Fluoride Micropore Membranes as Solid-Phase Extraction Disk for Preconcentration of Nanoparticulate Silver in Environmental Waters
}

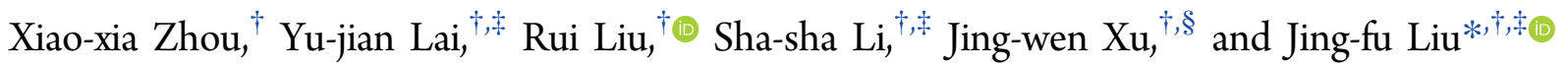 \\ ${ }^{\dagger}$ State Key Laboratory of Environmental Chemistry and Ecotoxicology, Research Center for Eco-Environmental Sciences, Chinese \\ Academy of Sciences, P.O. Box 2871, Beijing 100085, China \\ ${ }^{\ddagger}$ University of Chinese Academy of Sciences, Beijing 100049, China \\ ${ }^{\S}$ College of Environment, Liaoning University, Shenyang 110036, China
}

Supporting Information

\begin{abstract}
Efficient separation and preconcentration of trace nanoparticulate silver (NAg) from large-volume environmental waters is a prerequisite for reliable analysis and therefore understanding the environmental processes of silver nanoparticles (AgNPs). Herein, we report the novel use of polyvinylidene fluoride (PVDF) filter membrane for disk-based solid phase extraction (SPE) of NAg in $1 \mathrm{~L}$ of water samples with the disk-based SPE system, which consists of a syringe pump and a syringe filter holder to embed the filter membrane. While the PVDF membrane can selectively adsorb NAg in the presence of $\mathrm{Ag}^{+}$,

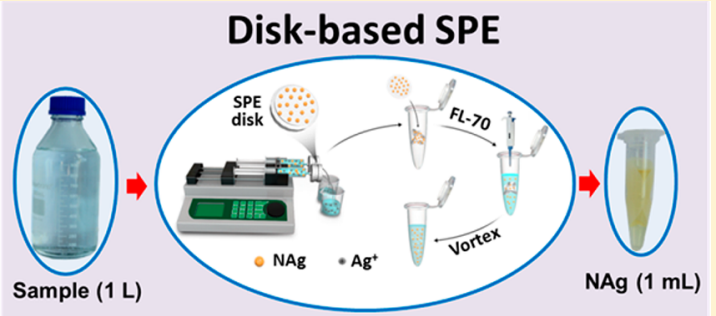
aqueous solution of $2 \%(\mathrm{~m} / \mathrm{v})$ FL-70 is found to efficiently elute NAg. Analysis of NAg is performed following optimization of filter membrane and elution conditions with an enrichment factor of 1000. Additionally, transmission electron microscopy (TEM), UV-vis spectroscopy, and size-exclusion chromatography coupled with ICP-MS (SEC-ICP-MS) analysis showed that the extraction gives rise to no change in NAg size or shape, making this method attractive for practical applications. Furthermore, feasibility of the protocol is verified by applying it to extract NAg in four real waters with recoveries of $62.2-80.2 \%$ at $0.056-0.58 \mu \mathrm{g} / \mathrm{L}$ spiked levels. This work will facilitate robust studies of trace $\mathrm{NAg}$ transformation and their hazard assessments in the environment.
\end{abstract}

\section{INTRODUCTION}

The excellent optical, electronic, and chemical properties of engineered nanoparticles (ENPs) have led to their increased incorporation into industrial materials and consumer goods. ${ }^{1-3}$ However, inappropriate handling of these ENPs may create environmental hazards. During the production, handling and disposal of ENPs and ENP-enabled products, there is an increased likelihood of discharging ENPs into the environment that potentially affect organisms, and general population. ${ }^{4-9}$ Thus, it is highly desirable to better understand the environmental behaviors and toxic effects of ENPs. This strongly relies on accurate analytical methods for mass quantification, composition identification, and size characterization of ENPs.

Over the past decade, significant efforts have been made toward the development of analytical methods of ENPs. Typically, microscopic and spectroscopic techniques, including transmission electron microscopy (TEM), scanning electron microscopy (SEM), and dynamic light scattering (DLS), have been employed for size characterization, while ultravioletvisible spectroscopy (UV-vis), energy dispersive X-ray spectroscopy (EDS), and X-ray adsorption near edge spectroscopy (XANES) have been applied for composition identification. The coupling of size-based separation techniques, including size-exclusion chromatography (SEC), ${ }^{10-12}$ field-flow fraction (FFF) ${ }^{13,14}$ capillary electrophoresis (CE), ${ }^{15}$ thin layer chromatography (TLC), ${ }^{16}$ and hydrodynamic chromatography (HDC), ${ }^{17-19}$ with element-specific detectors such as inductively coupled plasma mass spectrometry (ICP-MS), have been used to quantify the mass and determine the average size of ENPs. ${ }^{14,20}$ However, due to the extremely low concentration of ENPs (in sub-microgram per liter range) and the complex matrixes, these methods are often difficult to meet the requirements for analysis of ENPs in the environment. ${ }^{21}$ Another promising technique for ENP analysis is single-particle inductively coupled plasma mass spectrometry (spICPMS). ${ }^{22-24}$ Although this technique is suitable for analyzing environmental/biological samples at low concentrations (ng/ L), spICP-MS is hindered by its size detection limits (10-40 $\mathrm{nm}) .^{22,23}$ Very recently, a promising spICP-MS method for silver-based nanoparticle (Ag-b-NP) determination was introduced by $\mathrm{Li}$ et al. ${ }^{25}$ Combined with $\mathrm{CPE}$, however, this technique only bears a great potential for detection of Ag-b-

Received: August 7, 2017

Revised: October 17, 2017

Accepted: November 9, 2017

Published: November 9, 2017 
NPs with sizes of $>14 \mathrm{~nm}$. Hence, a separation step is highly required for preconcentrating ENPs from a large volume of water to provide a high enrichment factor and at the same time preserving their size and shape, followed by mass quantification, composition identification, and size characterization of ENPs with the existing techniques.

Many approaches such as ultrafiltation (UF), ${ }^{26,27}$ ultracentrifugation (UC), ${ }^{28}$ solid phase extraction (SPE), ${ }^{29,30}$ capillary microextraction (CME), ${ }^{31,32}$ cloud point extraction (CPE), ${ }^{33-35}$ and ion-exchange resin method (IER), ${ }^{36,37}$ have been developed for separation and concentration of ENPs from environmental waters; however, most of these methods suffered from either the limited applicability for only small sample volumes, the nonsufficient enrichment, or the agglomeration of ENPs. To overcome these limitations, there is an urgent need for general, simple, and cost-effective approaches for extracting trace ENPs.

Herein, for the first time, we have developed a novel diskbased SPE for the semiautomated enrichment of nanoparticulate $\mathrm{Ag}$ (NAg), including silver nanoparticles (AgNPs) and silver sulfide nanoparticles $\left(\mathrm{Ag}_{2} \mathrm{~S} \mathrm{NPs}\right)$, from a large volume of environmental waters (1L) along with subsequent analysis by ICP-MS, TEM, SEC coupled with ICP-MS (SECICP-MS), and UV-vis spectrometric techniques (Scheme 1). It

Scheme 1. Preconcentration of NAg by Disk-Based SPE for Quantification, Characterization, and Identification

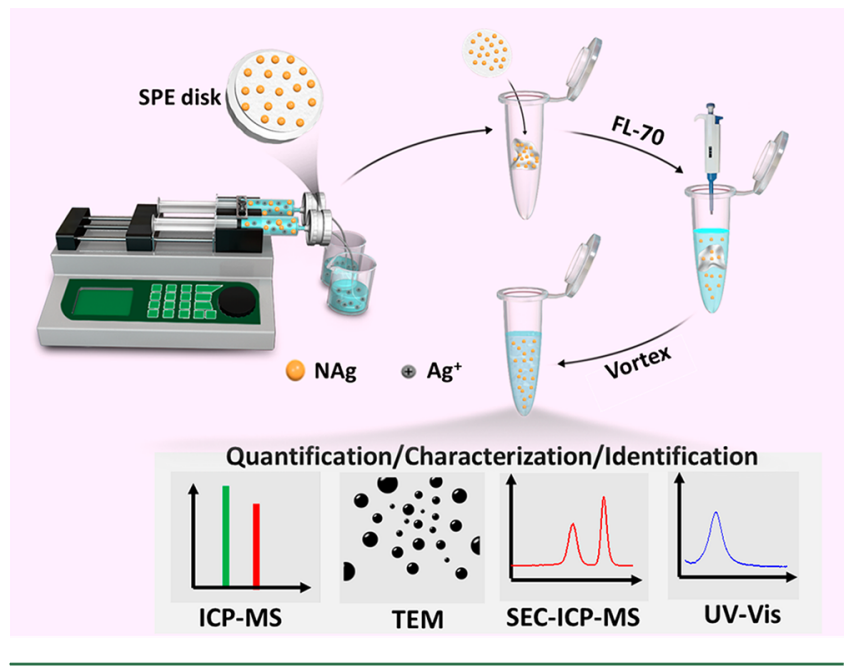

should be noted that as it is not possible to specify these silvercontaining NPs, we designate these particles as NAg. We found that NPs in the environmental waters can be adsorbed onto the filter membrane upon filtration with $0.45 \mu \mathrm{m}$ pore size filters. Moreover, these adsorbed NPs can be eluted with $2 \%(\mathrm{~m} / \mathrm{v})$ FL-70 (a surfactant) without disturbing their sizes and shapes, allowing for the separation and preconcentration of trace NPs from environmental waters. The proposed disk-based SPE offers several distinct advantages: (1) a semiautomated filtration with a controllable speed and volume using a syringe pump, (2) protecting sizes and shapes of NAg during preconcentration process, and (3) highly sensitive NAg mass quantification, composition identification, and size characterization in environmental waters (low $\mathrm{ng} / \mathrm{L}$ ).

\section{MATERIAL AND METHODS}

Chemical and Materials. Commercial filter membranes (25 $\mathrm{mm}$ in diameter, $0.45 \mu \mathrm{m}$ pore size) made from different materials, including polyvinylidene fluoride (PVDF), poly(ether sulfone) (PES), polytetrafluoroethylene (PTFE), nylon, and mixed cellulose ester (MCE), were purchased from Jinteng Instrument Co. (Tianjin, China). Another polyprolene filter membrane $(25 \mathrm{~mm}$ in diameter, $0.45 \mu \mathrm{m}$ pore size) was obtained from Wings Instrument Co. (Shanghai, China). Highspeed qualitative filter papers were purchased from Whatman Xinhua Filter Paper Co. (Hangzhou, China). Citrate-stabilized AgNPs with nominal particle sizes of $10,20,40$, and $60 \mathrm{~nm}$ were obtained from Sigma-Aldrich (St. Louis, MO), while polyvinylpyrrolidone (PVP)-coated AgNPs with nominal particle sizes of $10,20,40$, and $60 \mathrm{~nm}$ were purchased from nanoComposix (San Diego, CA). TEM images and size distributions of commercial AgNPs ranging from 20 to 60 $\mathrm{nm}$ are shown in Figure $\mathrm{S} 1$, and the contents of $\mathrm{Ag}^{+}$in these AgNP dispersions, analyzed with our previously reported SECICP-MS method, ${ }^{12}$ were found less than $1.8 \%$. FL-70, a mixture of anionic and nonionic surfactants, containing sodium carbonate, tetrasodium ethylene diamine tetraacetate, poly-

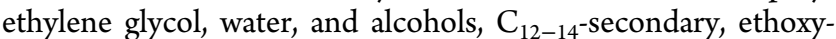
lated, was obtained from Fisher Scientific (Fair Lawn, NJ). $\mathrm{Ag}^{+}$ standard in $5 \%(\mathrm{v} / \mathrm{v}) \mathrm{HNO}_{3}$ aqueous solution $(1000 \mathrm{mg} / \mathrm{L})$ used for ICP-MS was obtained from National Institute of Metrology (Beijing, China). Nitric acid (65\%) was obtained from Merck (Darmstadt, Germany). Other reagents were purchased from Beijing Chemicals (Beijing, China). All the reagents were used as obtained without additional purification. Ultrapure water $(18.3 \mathrm{M} \Omega$ ) produced with a Milli-Q gradient system (Millipore, Billerica, MA) was used throughout the experiments.

Disk-Based SPE of NAg. Scheme 1 shows the disk-based SPE setup which comprises a syringe pump (LongerPump, Shanghai, China) with two independent filtration units, enabling the processing of two different samples simultaneously without need of manual handling. Each unit consists of a $60 \mathrm{~mL}$ syringe, and a syringe filter holder $(25 \mathrm{~mm}$ in diameter, Pall, MI) embedded with a filter membrane. The system can extract aqueous samples continuously at a maximum flow rate of 80 $\mathrm{mL} / \mathrm{min}$.

For separation and concentration the NAg, a volume of aqueous sample $(100-2000 \mathrm{~mL}$ ) was filtered through the SPE disk by using the above-mentioned syringe pump at a constant flow rate of $30 \mathrm{~mL} / \mathrm{min}$. Then, the filter membrane loaded with $\mathrm{NAg}$ was taken out and transferred into a $1.5 \mathrm{~mL}$ conical centrifuge tube containing $1 \mathrm{~mL}$ of $2 \%(\mathrm{~m} / \mathrm{v})$ FL-70 aqueous solution, followed by shaking at $2500 \mathrm{rpm}$ for $6 \mathrm{~h}$ at room temperature with a multitube vortexer (Hangzhou Allsheng Instrument Co. Ltd., Zhejiang, China). The adsorption (\%) and recovery (\%) were calculated, respectively, by eqs 1 and 2 :

$$
\begin{aligned}
& \text { adsorption }(\%)=100-\frac{C_{\mathrm{f}}}{C_{0}} \times 100 \\
& \text { recovery }(\%)=\frac{C_{\mathrm{e}} \times V_{\mathrm{e}}}{C_{0} \times V_{0}} \times 100
\end{aligned}
$$

where $C_{0}(\mu \mathrm{g} / \mathrm{L})$ is the initial concentration of NAg before filtration, $C_{\mathrm{f}}(\mu \mathrm{g} / \mathrm{L})$ is the concentration of NAg in runoff, $C_{\mathrm{e}}$ $(\mu \mathrm{g} / \mathrm{L})$ is the concentration of NAg in the eluent, $V_{0}(\mathrm{~mL})$ is 

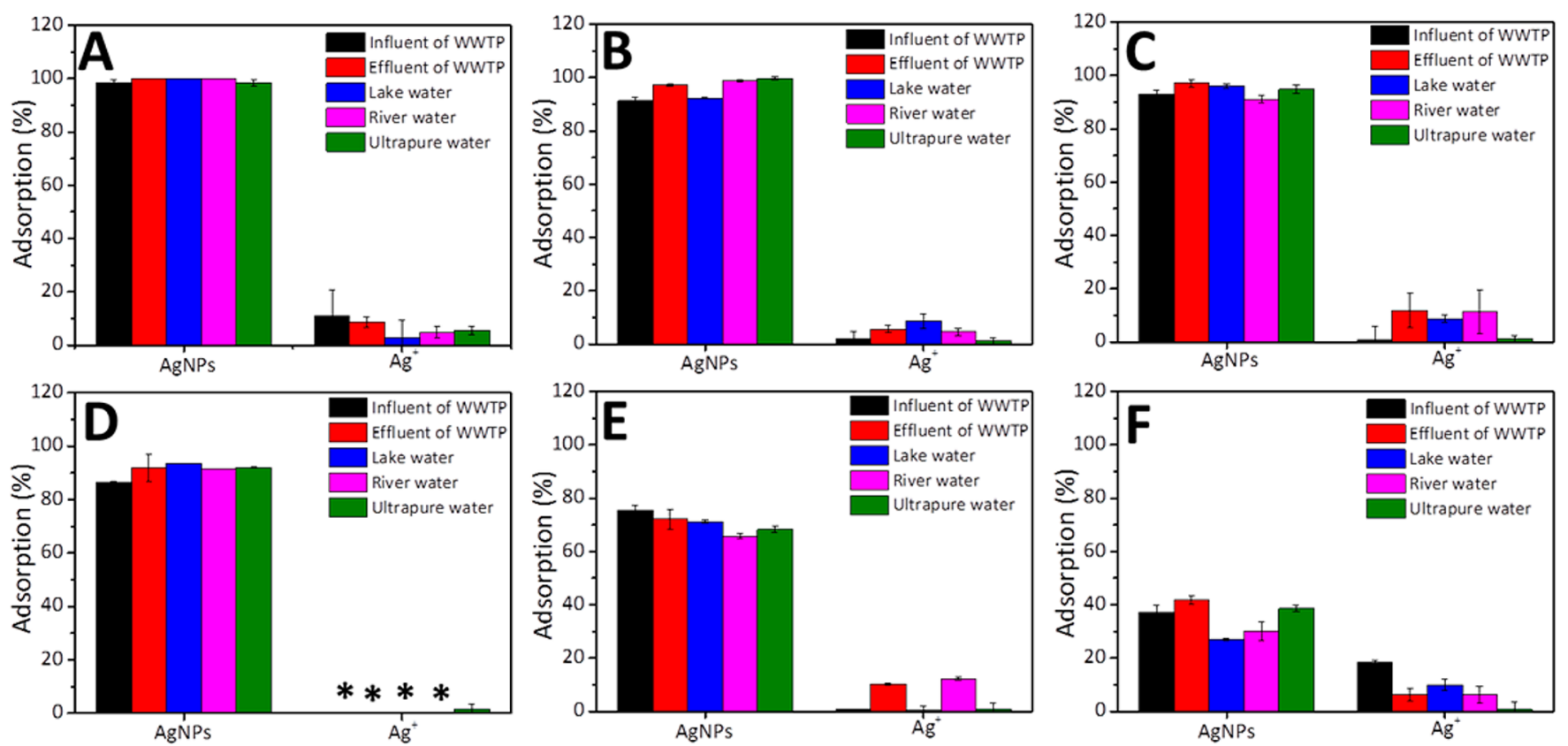

Figure 1. Adsorption of AgNPs and $\mathrm{Ag}^{+}$in the environmental waters onto the different filter membranes during filtration: (A) PVDF, (B) PES, (C) Nylon, (D) MCE, (E) PTFE, and (F) PP. The sample concentration and volume were $\sim 0.5 \mu \mathrm{g} / \mathrm{L} \mathrm{Ag}$ and $100 \mathrm{~mL}$, respectively. *The value is negative.

the initial volume of NAg before filtration, and $V_{\mathrm{e}}(\mathrm{mL})$ is the volume of the eluent $(1 \mathrm{~mL})$.

Water Sample Collection. River water was collected from the Kunyu river, lake water was taken from the Olympic park (Beijing, China), and the municipal sewage influent and effluent were retrieved from the Qinghe Wastewater Treatment Plant (WWTP). All of the waters were collected in the glass bottles, which were rinsed several times with the sample first, and filtered through a high-speed qualitative filter paper (80$120 \mu \mathrm{m}$ pore size) before use. Typical characteristics of these environmental waters, including $\mathrm{pH}$, and concentrations of total organic carbon (TOC) and different cations, were shown in Table S1.

\section{RESULTS AND DISCUSSION}

Filter Membrane Selection and NAg Preconcentration. Because of the dissolution of $\mathrm{NAg}, \mathrm{Ag}^{+}$always coexists with NAg in the aqueous samples, which would contribute a positive bias to the ICP-MS measurement of NAg. ${ }^{33}$ Therefore, to select the appropriate filter membrane that is capable of selectively adsorbing trace concentration of NAg, six commercial filter membranes $(0.45 \mu \mathrm{m}$ pore size $)$ made from different materials like PVDF, PES, nylon, MCE, PTFE, and $\mathrm{PP}$, were examined by filtering $0.5 \mu \mathrm{g} / \mathrm{L} 10 \mathrm{~nm}$ citrate-coated AgNPs and $\mathrm{Ag}^{+}$spiked, respectively, in different real waters including influent and effluent of WWTP, lake water, and river water. As shown in Figure 1, filter membranes of PVDF, PES, nylon and MCE exhibited the highest selectivity to AgNPs, followed by PTFE, and then PP. For the PVDF, PES, nylon and MCE filter membranes, the adsorptions were $86.5-100 \%$ for AgNPs and $0-11.5 \%$ for $\mathrm{Ag}^{+}$. For PTFE and PP filter membranes, though most of $\mathrm{Ag}^{+}$passed through the filter with adsorption of $<18.2 \%$, only $26.9-75.5 \%$ of AgNPs were collected (Figure $1 \mathrm{E}$ and $1 \mathrm{~F}$ ). On the basis of the above result, it is safe to conclude that most of AgNPs in the environmental waters could not pass through the filters, though the pore size of the nominal filter membrane $(0.45 \mu \mathrm{m})$ was far larger than the diameter of AgNPs (10 nm). Additionally, the similar results found for AgNPs in ultrapure water and environmental waters suggested that the adsorption of AgNPs was mainly caused by their adsorption onto the filter membrane, rather than onto the suspended organic matters with sizes of $>0.45$ $\mu \mathrm{m}$, as reported previously. ${ }^{12,37}$

To understand the role of invisible suspended organic matters $(>0.45 \mu \mathrm{m})$ in the adsorption of $\mathrm{AgNPs} / \mathrm{Ag}^{+}$during filtration, two parallel experiments were performed. In the first experiment, environmental waters spiked with $\sim 0.5 \mu \mathrm{g} / \mathrm{L}$ AgNPs $/ \mathrm{Ag}^{+}$were shaken at $300 \mathrm{rpm}$ for $3 \mathrm{~h}$, followed by filtration with the above-mentioned types of filter membranes. In the second experiment, environmental waters were filtered with PES membrane $(0.45 \mu \mathrm{m}$ pore size $)$ prior to spiking of AgNPs $/ \mathrm{Ag}^{+}$in order to remove the suspended organic matters $(>0.45 \mu \mathrm{m})$, then the same procedure was conducted as described in the first experiment. No significant change of adsorptions was observed for $\mathrm{AgNPs} / \mathrm{Ag}^{+}$in all the filtered environmental waters along with their corresponding unfiltered samples (see Figures S2 and S3), indicating that the suspended organic matters $(>0.45 \mu \mathrm{m})$ have a limited effect on the adsorption of AgNPs $/ \mathrm{Ag}^{+}$on the filter membrane.

After confirming that the adsorption of $\mathrm{AgNPs} / \mathrm{Ag}^{+}$was mainly attributed to their adsorption onto the filter membrane, the effect of sample concentration was studied by determining the respective adsorption of $\mathrm{AgNPs}$ and $\mathrm{Ag}^{+}$at concentration levels ranging from 0.1 to $1000 \mu \mathrm{g} / \mathrm{L}$ in river water. For all the types of filter membranes, the adsorption of AgNPs remained at a certain level with concentrations ranging from 0.1 to $100 \mu \mathrm{g} /$ $\mathrm{L}$; however, a marked increase in the adsorption of $\mathrm{Ag}^{+}$was observed with concentrations in the range of $200-1000 \mu \mathrm{g} / \mathrm{L}$ (Figure S4). This might be attributed to the relatively high levels of inorganic anions in the river waters, which reacted with part of the $\mathrm{Ag}^{+}$to form insoluble nanoparticulate matters. ${ }^{38}$ To verify this, ultrapure water samples spiked with $200-1000 \mu \mathrm{g} / \mathrm{L}$ 


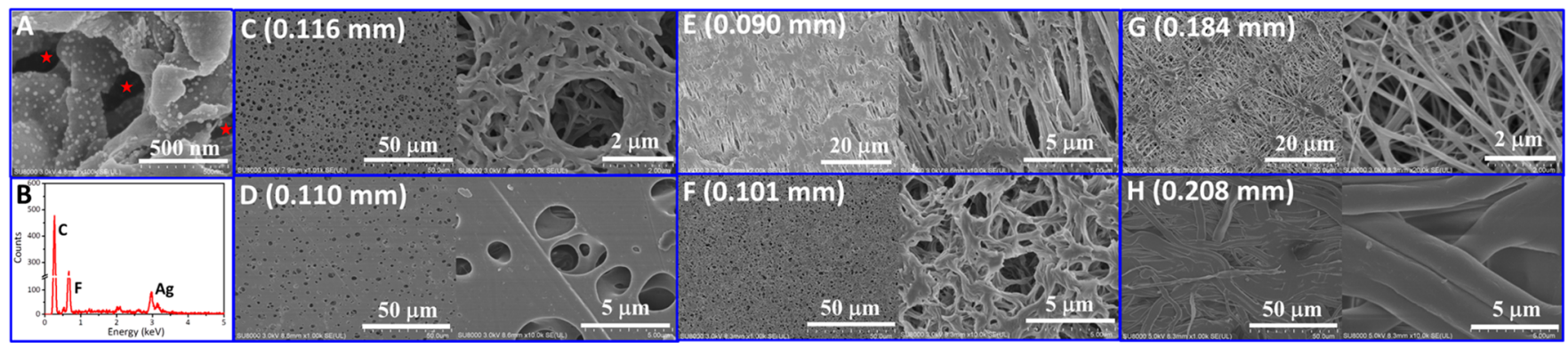

Figure 2. SEM images of PVDF filter membrane after adsorption of $10 \mathrm{~nm}$ citrate-coated AgNPs (A), the EDS spectra of the AgNPs on the membrane surface (B), and the SEM images of filter membranes (C-H): (C) PVDF, (D) PES, (E) nylon, (F) MCE, (G) PTFE, and (H) PP. The data in the parentheses is the thickness of the respective filter membrane. Note that the dark area marked with red stars in (A) represents the hole of the filter membrane, while the white dots are the adsorbed AgNPs.
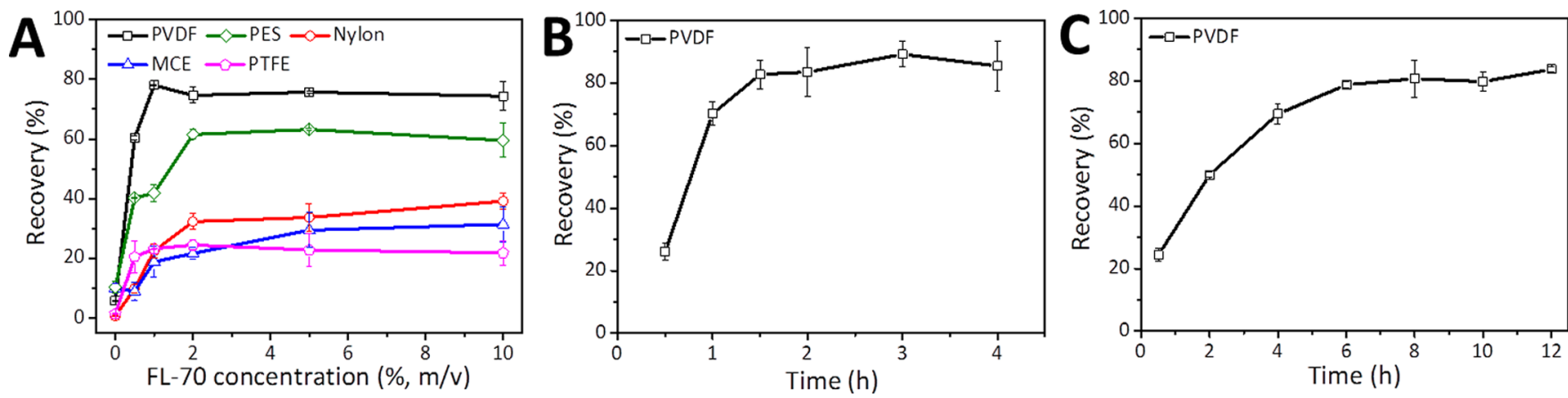

Figure 3. Elution of the AgNPs adsorbed on the filter membranes after filtration of river water samples spiked with AgNPs. (A) Elution with different concentrations of FL-70 under ultrasonication for $2 \mathrm{~h}$. (B) Elution with 2\% (m/v) FL-70 under ultrasonication for different time. (C) Elution with $2 \%(\mathrm{~m} / \mathrm{v})$ FL-70 under vortex for different time. The AgNP concentration and sample volume were $\sim 0.5 \mu \mathrm{g} / \mathrm{L}$ and $100 \mathrm{~mL}$, respectively.

$\mathrm{Ag}^{+}$were subjected to the same filtration as that of the river waters, and it was found that only $0.1-6.0 \%$ of $\mathrm{Ag}^{+}$was captured on the filter membranes (Figure S5), supporting our speculation.

Results shown in Figure S4 again indicates that regardless of the concentration, most of AgNPs were adsorbed onto the filter membrane during filtration, and the highest selectivity to AgNPs was obtained by PVDF, PES, nylon and MCE filter membrane, followed by PTFE and PP filter membrane. To demonstrate that the filter membrane mainly serve as adsorbent in this work, a PVDF filter membrane was added into $100 \mathrm{~mL}$ of citrate-coated AgNPs solution $(\sim 1 \mathrm{mg} / \mathrm{L})$, followed by shaking at $25{ }^{\circ} \mathrm{C}$ on an orbital shaker (IKA KS501) at $330 \mathrm{rpm}$ for $30 \mathrm{~min}$. It was observed that lots of AgNPs were distributed uniformly on the membrane surface without any aggregation or agglomeration (Figure $2 \mathrm{~A}$ and $2 \mathrm{~B}$ ). This result indicated that PVDF filter membrane is an efficient adsorbent for recovery of NAg from aqueous solution and that the procedure in Scheme 1 accords with the principal of the disk-based SPE. The detailed mechanism for this adsorption still remains unclear, though few studies have reported that NPs tend to be blocked onto the filter membrane. ${ }^{39,40}$ SEM analysis showed that PVDF, PES, nylon, and MCE filter membranes have similar porous structures that consists of sponge-like voids, while fiber-like and finger-like voids were observed for PTFE and PP membrane (Figure 2C-2H). This result suggests that the selectivity of NAg toward different filter membranes depends on their microphysical structures to some extent, as the highest selectivity was obtained by PVDF, PES, nylon, and MCE filter membranes with similar voids. Also, our ongoing research showed that the adsorption activity for NPs is closely associated with the chemical makeup of the filter membranes. However, future work is still needed to study the adsorption mechanism, and the factors affecting the selectivity to NAg and $\mathrm{Ag}^{+}$.

To quantitatively analyze and qualitatively characterize NAg, $\mathrm{NAg}$ adsorbed on the filter membranes have to be eluted without disturbing their physical status and chemical species. For the five filter membranes (PVDF, PES, nylon, MCE and PTFE) showed high adsorption to AgNPs (Figure 1 and Figure S4), the elution of the adsorbed AgNPs was evaluated by ultrasonication treating the filter membranes, immersed in 1 $\mathrm{mL}$ of different concentrations of FL-70, at $600 \mathrm{~W}$ for $2 \mathrm{~h}$. As shown in Figure 3A, the AgNP recoveries increased with FL-70 concentration up to $2 \%(\mathrm{~m} / \mathrm{v})$ for all the five investigated filter membranes, and PVDF filter membranes exhibited the highest recovery of AgNPs (>75\%). Therefore, PVDF filter membrane was adopted and $2 \%(\mathrm{~m} / \mathrm{v})$ FL-70 was used as eluent in the subsequent studies.

After the filter membrane and eluent were determined, ultrasonication time ranging from 0.5 to $4 \mathrm{~h}$ on the recovery of AgNPs was tested. As shown in Figure 3B, the highest recovery was achieved at a ultrasonication time of $1.5 \mathrm{~h}$. However, it should be noted that ultrasonication may lead to dissolution of metallic NPs and redispersion of NP aggregates, which have been observed in previous studies. ${ }^{41-43}$ To preserve the sizes and shapes of AgNPs, a relatively mild elution process is preferred. As shown in Figure 3C, a similar recovery rate of $\sim 78.8 \%$ was obtained by replacing ultrasonication with vortex (2500 rpm) for $6 \mathrm{~h}$.

We then tested if the vortex treatment could modify the physicochemical species of NAg. After vigorously shaking the mixture of $1 \mathrm{mg} / \mathrm{L}$ AgNPs in $2 \%(\mathrm{~m} / \mathrm{v})$ FL-70 aqueous 

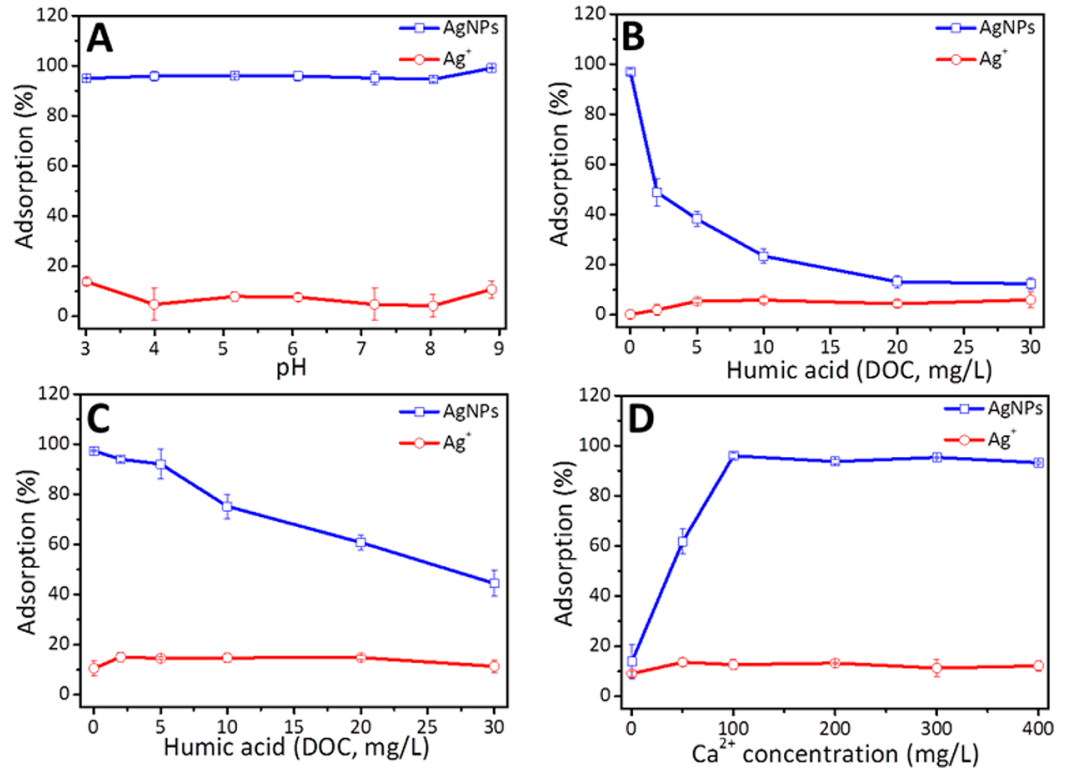

Figure 4. Effects of environmentally relevant parameters on the adsorption of AgNPs and $\mathrm{Ag}^{+}$onto the PVDF filter membrane. (A) Effect of pH on the adsorption of AgNPs and $\mathrm{Ag}^{+}$in ultrapure water; (B) Effect of humic acid on the adsorption of AgNPs and $\mathrm{Ag}^{+}$in ultrapure water; (D) Effect of $\mathrm{Ca}^{2+}$ on the adsorption of AgNPs and $\mathrm{Ag}^{+}$in ultrapure water containing HA of $20 \mathrm{mg} / \mathrm{L}$ DOC. The sample concentration and volume were $\sim 0.5$ $\mu \mathrm{g} / \mathrm{L} \mathrm{Ag}$ and $100 \mathrm{~mL}$, respectively.
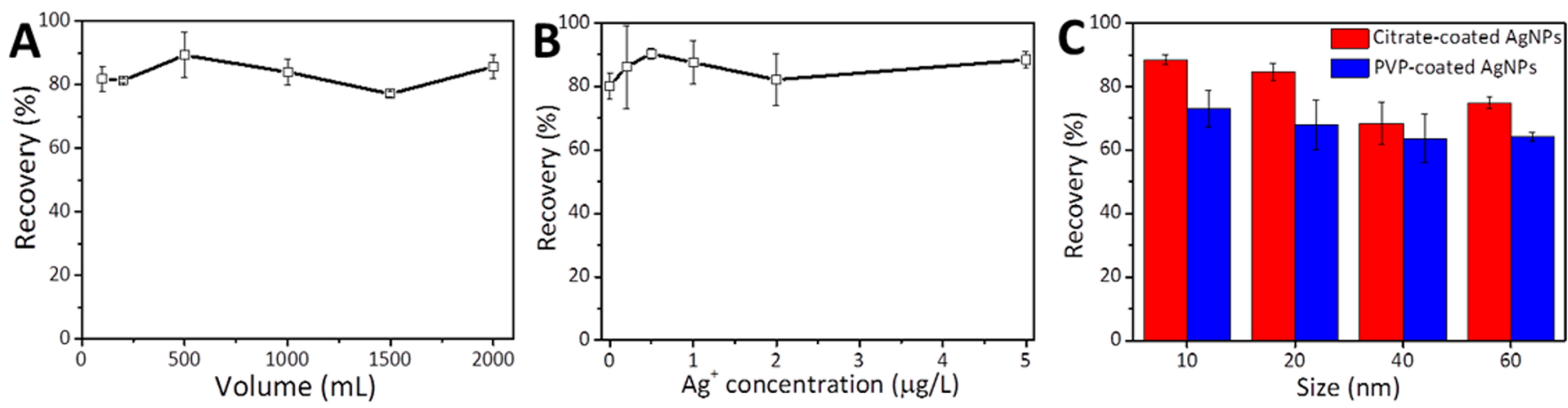

Figure 5. Effect of sample volume (A), $\mathrm{Ag}^{+}(\mathrm{B})$, and coatings and sizes of AgNPs (C) on the recovery of AgNPs by the disk-based SPE of AgNPs. River water samples spiked with AgNPs $(\sim 0.5 \mu \mathrm{g} / \mathrm{L})$ were extracted with the PVDF filter membrane followed by eluting with $2 \%$ (m/v) FL-70 under vortex for $6 \mathrm{~h}$.

solution at $2500 \mathrm{rpm}$ under vortex for 6 and $48 \mathrm{~h}$, respectively, the AgNPs was analyzed by TEM and SEC-ICP-MS. As shown in Figure S6, no significant change in particle size and shape was observed in TEM images. Also, the SEC-ICP-MS chromatogram at 6 and $48 \mathrm{~h}$ was found in perfect match with that of AgNP stock dispersion, indicating the high stability of AgNPs in FL-70 under vortex. Overall, our results showed that $2 \%(\mathrm{~m} / \mathrm{v})$ FL-70 is able to elute AgNPs adsorbed on the filter membrane efficiently and that a proper elution process (ultrasonication or vigorous shaking) can be selected based on the requirement of specific study.

Factors Influencing the Disk-Based SPE of NAg. To establish a method capable of selectively preconcentrating of $\mathrm{NAg}$ in the environmental waters, various parameters that commonly affect NP extraction were investigated. Figure $4 \mathrm{~A}$ illustrated the effect of $\mathrm{pH}$ on the adsorptions of AgNPs and $\mathrm{Ag}^{+}$, which were determined by filtering individual AgNPs and $\mathrm{Ag}^{+}$in ultrapure water $(0.5 \mu \mathrm{g} / \mathrm{L})$ at $\mathrm{pH}$ in the range of 3-9 with the PVDF filter membrane, in which little or no change in the adsorptions of $\mathrm{AgNPs}$ and $\mathrm{Ag}^{+}$was observed, indicating that the effect of $\mathrm{pH}$ on the NAg extraction was negligible.
Since it was reported that the dissolved organic matter (DOM), widely present in the environmental waters, can associate with NPs to form stable hydrosol,,$^{27,44}$ it is important to study the potential effect of DOM in an environmentally relevant concentration range $(0-30 \mathrm{mg} / \mathrm{L}$ dissolved organic carbon, DOC) on the extraction of AgNPs. Figure 4B shows the adsorption values for AgNPs and $\mathrm{Ag}^{+}$in ultrapure water containing different concentrations of humic acid (HA) as a model of DOM. While the addition of HA exerts a limited effect on the adsorption of $\mathrm{Ag}^{+}$, increased concentrations of $\mathrm{HA}$ significantly reduced the adsorption of AgNPs. The reduction of AgNP adsorption by HA was inconsistent with that in environmental waters (Figure 1), in which AgNPs were highly recovered in the presence of DOM (4.01-18.5 mg/L DOC, Table S1). We speculate that, the cations in real waters, especially $\mathrm{Ca}^{2+}$ and $\mathrm{Mg}^{2+}$, suppressed the interference of DOM for their bridging with DOM. ${ }^{43,45}$ To verify this, we first determined the respective adsorption of AgNPs and $\mathrm{Ag}^{+}$in river water with preaddition of HA. Results showed that the HA interference on the adsorption of AgNPs was alleviated significantly as compared with that in ultrapure water (Figure 

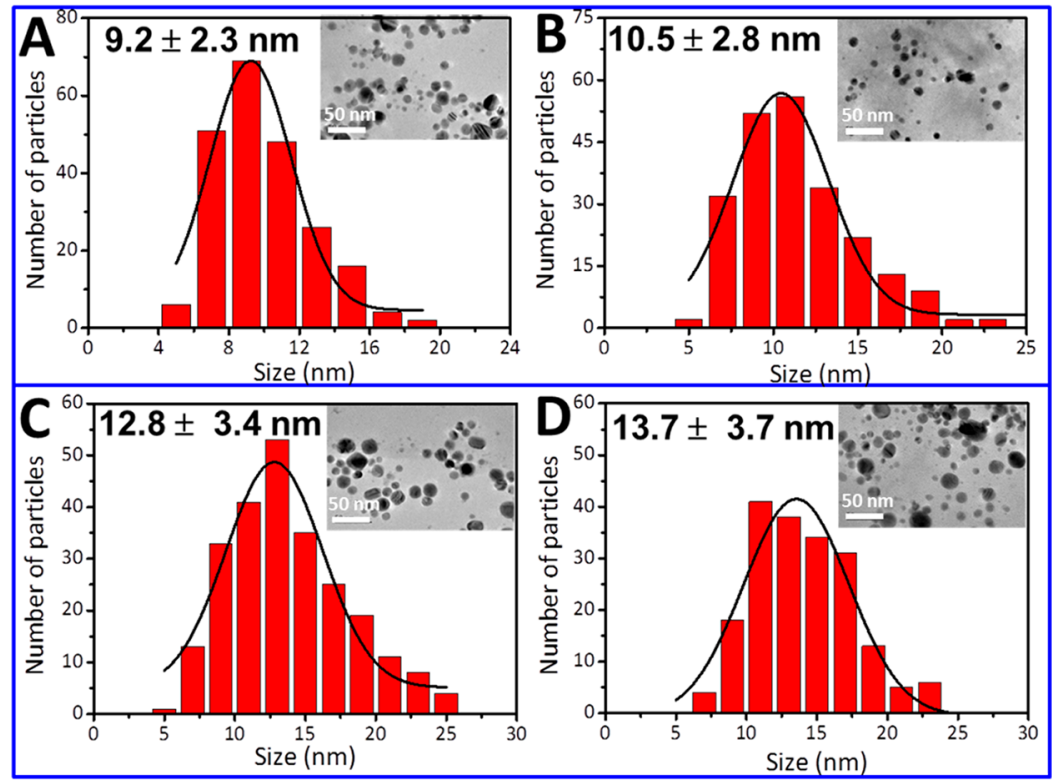

Figure 6. Size distributions and TEM images of citrate-coated AgNPs (A, B) and PVP-coated AgNPs (C, D) before (A, C) and after (B, D) diskbased SPE. The scale bar was $50 \mathrm{~nm}$.

4C). To further explore the role of cations played in the extraction of AgNPs, simulated samples prepared by spiking various concentrations of $\mathrm{Ca}^{2+}, \mathrm{AgNPs}$ or $\mathrm{Ag}^{+}(0.5 \mu \mathrm{g} / \mathrm{L})$, and $\mathrm{HA}(20 \mathrm{mg} / \mathrm{L}$ DOC) in ultrapure water were subjected to the extraction under the optimized conditions. As shown in Figure $4 \mathrm{D}, \mathrm{Ca}^{2+}$ showed strong capacity in suppressing the interference of $\mathrm{HA}$, and the addition of $100 \mathrm{mg} / \mathrm{L} \mathrm{Ca}^{2+}$ ensures the adsorption of $96.0 \%$ AgNPs in the presence of $20 \mathrm{mg} / \mathrm{L}$ DOC. Overall, it was found that though the widely presented DOM interferes with the extraction of AgNPs, it is markedly suppressed by the cations coexisted in the environment.

Due to the low concentration of AgNPs in environmental waters, extraction of a large volume of sample was required to ensure the high enrich factor and satisfy the low detection limit. Figure 5A shows the spiked recoveries of $0.5 \mu \mathrm{g} / \mathrm{L} \mathrm{AgNPs} \mathrm{in}$ river waters when the sample volume ranged from 100 to 2000 $\mathrm{mL}$. The high recoveries $(\geq 77.1 \%)$ indicates that the tested volume has a limited effect on the extraction of AgNPs. A sample volume of $1000 \mathrm{~mL}$ was adopted in the following studies to enable the proposed method applicable for real water samples that contain low content of NAg. It should be noted that real waters could hardly be filtered through the membrane after filtration of $200-300 \mathrm{~mL}$ of samples with traditional filtration methods such as negative-pressure, and manual filtration. In this method, however, due to the syringe pump providing high pressure, $2000 \mathrm{~mL}$ of river water could pass through the filter membrane with a constant flow rate of 30 $\mathrm{mL} / \mathrm{min}$.

Although the above study excluded the adsorption of $\mathrm{Ag}^{+}$by the filter membrane, $\mathrm{Ag}^{+}$might be coextracted with AgNPs by adsorption onto the surface of AgNPs, resulting in a positive error. In this regard, dispersions with constant AgNPs $(0.5 \mu \mathrm{g} /$ $\mathrm{L})$ and varied $\mathrm{Ag}^{+}$were premixed for $0.5 \mathrm{~h}$ and then extracted. Figure $5 \mathrm{~B}$ shows that AgNPs were extracted with similar recoveries in the range of $80.2-90.4 \%$, indicating that the interference of $\mathrm{Ag}^{+}$was negligible when $\mathrm{Ag}^{+}$concentration was no more than 10-fold of AgNPs. It is reported that $\mathrm{Ag}^{+}$ concentration comprises less than $0.1 \%$ of the total $\mathrm{Ag}$ in environmental waters. ${ }^{46}$ Hence, it is believed that the proposed method is applicable for most real waters.

In environmental waters, NAg with different sizes, coatings, and compositions are expected. Citrate- and PVP-coated AgNPs are the two main commercial AgNPs studied in the field of nanoanalysis and environmental process. ${ }^{14-16}$ Therefore, spiked recoveries of various sized citrate-coated and PVPcoated AgNPs $(10,20,40$, and $60 \mathrm{~nm})$ in river water were tested with the proposed method. All recoveries were found higher than $64.1 \%$, as shown in Figure 5C, and no significant differences were observed, indicating that the sizes and coatings had limited effects on the extraction of AgNPs. Further, we tested the applicability of the proposed method in extraction of $\mathrm{Ag}_{2} \mathrm{~S}$ NPs, another type of NAg widely present in the environment. Previous study has shown that the released AgNPs in the environment would readily undergo sulfidation to form the highly stable $\mathrm{Ag}_{2} \mathrm{~S}$ NPs. ${ }^{14}$ The good recovery of $72.4 \%$ for $\mathrm{Ag}_{2} \mathrm{~S} \mathrm{NPs}$ at the spiking level of $\sim 0.5 \mu \mathrm{g} / \mathrm{L}$ in river water suggests the high potential of the proposed method for extraction of NAg from waters.

Size and Shape Preservation of NAg. Besides selective enrichment of AgNPs, the issue of preserving the AgNP sizes and shapes is also of great importance. Many studies have reported that the aggregation of AgNPs would lead to the redshift and broadening of UV-vis spectra, and the darkening of AgNP hydrosol. ${ }^{27}$ Considering the significant changes in the size distribution of AgNPs in real waters, ${ }^{12}$ AgNPs were spiked into the ultrapure water instead of real water and then enriched with the proposed method to observe the size and shape changes caused by extraction procedure (Figure S7). Results showed that AgNPs in the eluent were still bright yellow with a very slight red shift of absorbance $\left(\lambda_{\max }\right)$ from 395 to $402 \mathrm{~nm}$ due to the transfer of solvent from pure water to a mixture of FL-70 (surfactant) eluent, indicating that no obvious aggregation of particles have occurred during extraction procedure. This conclusion is further supported by TEM analysis of AgNPs before and after extraction. As shown in Figure 6, the respective size distributions before and after extraction were of $9.2 \pm 2.3$ and $10.5 \pm 2.8 \mathrm{~nm}$ for citrate- 
Table 1. Quantification, Characterization, and Identification of NAg in Environmental Waters after Preconcentration by the Proposed Method

\begin{tabular}{|c|c|c|c|c|c|c|}
\hline \multirow[b]{2}{*}{ sample } & \multirow[b]{2}{*}{ spiked AgNPs $(\mu \mathrm{g} / \mathrm{L})$} & \multirow[b]{2}{*}{ detected $\mathrm{Ag}(\mu \mathrm{g} / \mathrm{L})$} & \multirow[b]{2}{*}{ recovery $(\%)$} & \multicolumn{3}{|c|}{ characterization and identification of NPs } \\
\hline & & & & SEC-ICP-MS & UV-vis & TEM \\
\hline \multirow[t]{3}{*}{ influent of WWTP } & 0 & $0.0043 \pm 0.0007$ & & + & - & - \\
\hline & 0.056 & $0.039 \pm 0.002$ & $62.2 \pm 3.5$ & + & - & - \\
\hline & 0.56 & $0.41 \pm 0.02$ & $72.2 \pm 3.3$ & + & - & + \\
\hline \multirow[t]{3}{*}{ effluent of WWTP } & 0 & $0.0018 \pm 0.0002$ & & - & - & - \\
\hline & 0.058 & $0.044 \pm 0.002$ & $73.4 \pm 3.5$ & + & - & - \\
\hline & 0.58 & $0.47 \pm 0.01$ & $80.2 \pm 2.1$ & + & - & + \\
\hline \multirow[t]{3}{*}{ lake water } & 0 & $0.0018 \pm 0.0003$ & & + & - & - \\
\hline & 0.056 & $0.038 \pm 0.004$ & $64.4 \pm 7.9$ & + & - & - \\
\hline & 0.56 & $0.40 \pm 0.03$ & $71.7 \pm 5.8$ & + & - & + \\
\hline \multirow[t]{3}{*}{ river water } & 0 & $0.0020 \pm 0.0005$ & & - & - & - \\
\hline & 0.058 & $0.037 \pm 0.001$ & $62.3 \pm 1.5$ & + & + & - \\
\hline & 0.58 & $0.46 \pm 0.03$ & $79.5 \pm 4.4$ & + & + & + \\
\hline
\end{tabular}

coated AgNPs and $12.8 \pm 3.4$ and $13.7 \pm 3.7 \mathrm{~nm}$ for PVPcoated AgNPs, respectively.

Analytical Performance. To evaluate the analytical performance, different parameters including linearity of calibration curve, reproducibility, limit of detection, and enrichment factor, were investigated. By analyzing 9 standard solutions containing $0,0.05,0.1,0.2,0.5,1,2,5$, and $10 \mu \mathrm{g} / \mathrm{L}$ AgNPs, respectively, a linear calibration curve was obtained with a satisfactory correlation coefficient $\left(R^{2}\right)$ of 0.9979 . The reproducibility was evaluated by extracting 5 river water samples spiked with $0.5 \mu \mathrm{g} / \mathrm{L}$ AgNPs. The recovery and relative standard deviation (RSD) was noticed as $79.9 \%$ and $3.8 \%$, respectively. The limit of detection (LOD), defined as 3 times of the baseline noise $(S / N=3)$, was $0.2 \mathrm{ng} / \mathrm{L}$. The enrichment factor, calculated as the ratio of sample volume $(1000 \mathrm{~mL})$ to eluent volume $(1 \mathrm{~mL})$, was 1000 .

Real Sample Analysis. Four real environmental waters, namely, influent and effluent of a WWTP, lake water, and river water, were first characterized and then analyzed with the proposed method. As shown in Table S1, the four tested waters showed neutral or weakly alkaline, concentrations of DOC in the range of $4.01-18.5 \mathrm{mg} / \mathrm{L}$, concentrations of common cations $\left(\mathrm{Na}^{+}, \mathrm{K}^{+}, \mathrm{Mg}^{2+}\right.$, and $\left.\mathrm{Ca}^{2+}\right)$ from 4.6 to $135 \mathrm{mg} / \mathrm{L}$, and the turbidity, an important parameter that reflects the amount of the suspended solids, in the range of 3.69-144 NTU. The $\mathrm{Ag}$ content in the tested environmental waters was found in the range of $0.0018-0.0043 \mu \mathrm{g} / \mathrm{L}$ (Table 1). For the influent of WWTP and lake water, the detected Ag was Ag-containing NPs as identified by the SEC-ICP-MS method (Figure S8). Parallel to this, the Ag in the effluent of WWTP, and river water, should be $\mathrm{Ag}^{+}$or Ag-containing aggregates, as no Ag-containing nanoparticles were detected during TEM, SEC-ICP-MS, and UV-vis analysis. Then, to further evaluate the reliability, recoveries were determined by spiking $0.056-0.58 \mu \mathrm{g} / \mathrm{L}$ AgNPs into the four tested waters. Meanwhile, to approach the real environment as near as possible, samples were kept shaking at $330 \mathrm{rpm}$ for $\sim 1 \mathrm{~h}$ after spiking with AgNPs. It should be noted that a few models have been applied to quantitatively estimate the environmental concentrations of $\mathrm{NAg}^{47-50} \mathrm{As}$ summarized by Gottschalk et al., ${ }^{48}$ the predicted environmental concentration (PEC) in waters ranged from hundreds of $\mathrm{pg} / \mathrm{L}$ to tens of $\mu \mathrm{g} / \mathrm{L}$, of which the highest and lowest values are pronounced with a factor of $\sim 10^{5}$ difference. However, there are some data available that might be conductive to know the environmental concentration of NAg. Li et al. ${ }^{37}$ analyzed the field-collection samples from 9 WWTPs in Germany. The NAg concentrations were $0.06-1.5 \mu \mathrm{g} / \mathrm{L}$ in the influent and $1.0-$ $12.0 \mathrm{ng} / \mathrm{L}$ in the effluent, respectively. Additionally, a NAg concentration of $100 \mathrm{ng} / \mathrm{L}$ was found in the effluent of a WWTP in USA. ${ }^{39}$ Therefore, recoveries of real samples at the reasonable spiking levels of $0.056-0.58 \mu \mathrm{g} / \mathrm{L}$ were determined. All samples were investigated after filtration with high-speed qualitative filter paper $(80-120 \mu \mathrm{m}$ pore size) to remove the visible suspended solids. As shown in Table 1, the recoveries for these samples were in the range of $62.2-80.2 \%$, suggesting that the proposed method is able to quantitatively separate and preconcentrate AgNPs from environmental waters, which will contribute to studying the environmental process of AgNPs.For all the spiked samples, only in river water AgNPs were observed with UV-vis (Figure S9), which might be ascribed to the simple matrix in the river water that had no interference on the UV-vis characterization of AgNPs. In the TEM images, nanoparticles were observed only for water samples spiked with $0.58 \mu \mathrm{g} / \mathrm{L}$ AgNPs, and the number of observable nanoparticles was very limited (Figure S10). These results indicated that combined multiple methods have to be used for characterization and identification of NAg in environmental samples because of their extremely low concentration and rather complex matrices.

To test if the filtration with high-speed qualitative filter paper will cause systematic error, the mass loss of $\mathrm{AgNPs} / \mathrm{Ag}^{+}$were evaluated by determining the recovery of $\mathrm{AgNPs} / \mathrm{Ag}^{+}$in four real waters and ultrapure water at a spiking level of $\sim 0.5 \mu \mathrm{g} / \mathrm{L}$. As shown in Figure S11, the recoveries of $\mathrm{AgNPs}$ and $\mathrm{Ag}^{+}$were $83.7-105 \%$ and $86.2-112 \%$, respectively, indicating that the filtration with high-speed qualitative filter paper resulted in negligible mass loss of AgNPs and $\mathrm{Ag}^{+}$. This can be attributed to the fact that only a small amount of visible suspended solids exist in these waters. It should be noted that the NAg determined in the present study mainly includes species of free $\mathrm{NAg}$, and the NAg adsorbed on the invisible suspended solids with sizes of $<80-120 \mu \mathrm{m}$ in environmental waters.

In summary, the PVDF membrane is for the first time demonstrated as an efficient disk-based SPE adsorbent in selective separation and preconcentration of trace NAg while preserving their sizes and shapes. The mass quantification of NAg was realized using ICP-MS determination with an extremely low detection limit $(0.2 \mathrm{ng} / \mathrm{L})$. Furthermore, as no changes in sizes and shapes of NAg occurred in the extraction procedure, the size distribution and composition of original 
NAg in the environment can be accomplished through direct characterization and identification of NAg preconcentrated in the eluent by TEM, SEC-ICP-MS, and UV-vis. In comparison with the existing extraction approaches (e.g., UC, CPE, and SPE), this proposed disk-based SPE method is suitable for analysis of large-volume water, leading to an enrichment factor as high as 1000 . Therefore, the method can be expected as an attractive alternative in the identification of characterization of NPs. This study offers a highly sensitive method for mass quantification, size characterization, and composition identification of NAg in the environment, allowing for its potential contribution in studies related to the fate and toxicity of NAg at the environmentally related concentration.

\section{ASSOCIATED CONTENT}

\section{S Supporting Information}

The Supporting Information is available free of charge on the ACS Publications website at DOI: 10.1021/acs.est.7b04055.

Details about synthesis of NPs and additional references (PDF)

\section{AUTHOR INFORMATION}

\section{Corresponding Author}

*Tel.: +86-10-62849192. Fax: +86-10-62849192. E-mail: jfliu@ rcees.ac.cn.

ORCID

Rui Liu: 0000-0001-6353-6193

Jing-fu Liu: 0000-0001-7134-7026

Notes

The authors declare no competing financial interest.

\section{ACKNOWLEDGMENTS}

This work was supported by the National Key R\&D Program of China (2016YFA0203102), the Strategic Priority Research Program of the Chinese Academy of Sciences (XDB14020101), and the National Natural Science Foundation of China (21337004, 21620102008).

\section{REFERENCES}

(1) Maynard, A. D.; Aitken, R. J.; Butz, T.; Colvin, V.; Donaldson, K.; Oberdoerster, G.; Philbert, M. A.; Ryan, J.; Seaton, A.; Stone, V.; Tinkle, S. S.; Tran, L.; Walker, N. J.; Warheit, D. B. Safe Handling of Nanotechnology. Nature 2006, 444, 267-269.

(2) Nowack, B.; Krug, H. F.; Height, M. 120 Years of Nanosilver History: Implications for Policy Makers. Environ. Sci. Technol. 2011, 45, 1177-1183.

(3) Chernousova, S.; Epple, M. Silver as Antibacterial Agent: Ion, Nanoparticle, and Metal. Angew. Chem., Int. Ed. 2013, 52, 1636-1653.

(4) Benn, T. M.; Westerhoff, P. Nanoparticle Silver Released into Water from Commercially Available Sock Fabrics. Environ. Sci. Technol. 2008, 42, 4133-4139.

(5) Geranio, L.; Heuberger, M.; Nowack, B. The Behavior of Silver Nanotextiles during Washing. Environ. Sci. Technol. 2009, 43, 81138118.

(6) He, D.; Dorantes-Aranda, J. J.; Waite, T. D. Silver NanoparticleAlgae Interactions: Oxidative Dissolution, Reactive Oxygen Species Generation and Synergistic Toxic Effects. Environ. Sci. Technol. 2012, 46, 8731-8738.

(7) Cunningham, S.; Brennan-Fournet, M. E.; Ledwith, D.; Byrnes, L.; Joshi, L. Effect of Nanoparticle Stabilization and Physicochemical Properties on Exposure Outcome: Acute Toxicity of Silver Nanoparticle Preparations in Zebrafish (Danio rerio). Environ. Sci. Technol. 2013, 47, 3883-3892.
(8) Wang, Z.; Liu, S.; Ma, J.; Qu, G.; Wang, X.; Yu, S.; He, J.; Liu, J.; Xia, T.; Jiang, G. B. Silver Nanoparticles Induced RNA PolymeraseSilver Binding and RNA Transcription Inhibition in Erythroid Progenitor Cells. ACS Nano 2013, 7, 4171-4186.

(9) Yang, X.; Jiang, C.; Hsu-Kim, H.; Badireddy, A. R.; Dykstra, M.; Wiesner, M.; Hinton, D. E.; Meyer, J. N. Silver Nanoparticle Behavior, Uptake, and Toxicity in Caenorhabditis elegans: Effects of Natural Organic Matter. Environ. Sci. Technol. 2014, 48, 3486-3495.

(10) Soto-Alvaredo, J.; Montes-Bayon, M.; Bettmer, J. Speciation of Silver Nanoparticles and Silver(I) by Reversed-Phase Liquid Chromatography Coupled to ICPMS. Anal. Chem. 2013, 85, 13161321.

(11) Zhou, X. X.; Liu, R.; Liu, J. F. Rapid Chromatographic Separation of Dissoluble $\mathrm{Ag}(\mathrm{I})$ and Silver-Containing Nanoparticles of 1-100 Nanometer in Antibacterial Products and Environmental Waters. Environ. Sci. Technol. 2014, 48, 14516-14524.

(12) Zhou, X. X.; Liu, J. F.; Jiang, G. B. Elemental Mass Size Distribution for Characterization, Quantification and Identification of Trace Nanoparticles in Serum and Environmental Waters. Environ. Sci. Technol. 2017, 51, 3892-3901.

(13) Barahona, F.; Geiss, O.; Urban, P.; Ojea-Jimenez, I.; Gilliland, D.; Barrero-Moreno, J. Simultaneous Determination of Size and Quantification of Silica Nanoparticles by Asymmetric Flow Field-Flow Fractionation Coupled to ICPMS Using Silica Nanoparticles Standards. Anal. Chem. 2015, 87, 3039-3047.

(14) Pettibone, J. M.; Liu, J. In Situ Methods for Monitoring Silver Nanoparticle Sulfidation in Simulated Waters. Environ. Sci. Technol. 2016, 50, 11145-11153.

(15) Franze, B.; Engelhard, C. Fast Separation, Characterization, and Speciation of Gold and Silver Nanoparticles and Their Ionic Counterparts with Micellar Electrokinetic Chromatography Coupled to ICP-MS. Anal. Chem. 2014, 86, 5713-5720.

(16) Yan, N.; Zhu, Z.; Jin, L.; Guo, W.; Gan, Y.; Hu, S. Quantitative Characterization of Gold Nanoparticles by Coupling Thin Layer Chromatography with Laser Ablation Inductively Coupled Plasma Mass Spectrometry. Anal. Chem. 2015, 87, 6079-6087.

(17) Pergantis, S. A.; Jones-Lepp, T. L.; Heithmar, E. M. Hydrodynamic Chromatography Online with Single Particle-Inductively Coupled Plasma Mass Spectrometry for Ultratrace Detection of Metal-Containing Nanoparticles. Anal. Chem. 2012, 84, 6454-6462.

(18) Rakcheev, D.; Philippe, A.; Schaumann, G. E. Hydrodynamic Chromatography Coupled with Single Particle-Inductively Coupled Plasma Mass Spectrometry for Investigating Nanoparticles Agglomerates. Anal. Chem. 2013, 85, 10643-10647.

(19) Lewis, D. J. Hydrodynamic Chromatography - Inductively Coupled Plasma Mass Spectrometry, with Post-Column Injection Capability for Simultaneous Determination of Nanoparticle Size, Mass Concentration and Particle Number Concentration (HDC-PCi-ICPMS). Analyst 2015, 140, 1624-1628.

(20) Liu, J.; Murphy, K. E.; MacCuspie, R. I.; Winchester, M. R. Capabilities of Single Particle Inductively Coupled Plasma Mass Spectrometry for the Size Measurement of Nanoparticles: A Case Study on Gold Nanoparticles. Anal. Chem. 2014, 86, 3405-3414.

(21) Leopold, K.; Philippe, A.; Wörle, K.; Schaumann, G. E. Analytical Strategies to the Determination of Metal-Containing Nanoparticles in Environmental Waters. TrAC, Trends Anal. Chem. 2016, 84, 107-120.

(22) Lee, S.; Bi, X.; Reed, R. B.; Ranville, J. F.; Herckes, P.; Westerhoff, P. Nanoparticle Size Detection Limits by Single Particle ICP-MS for 40 Elements. Environ. Sci. Technol. 2014, 48, 1029110300.

(23) Gray, E. P.; Coleman, J. G.; Bednar, A. J.; Kennedy, A. J.; Ranville, J. F.; Higgins, C. P. Extraction and Analysis of Silver and Gold Nanoparticles from Biological Tissues Using Single Particle Inductively Coupled Plasma Mass Spectrometry. Environ. Sci. Technol. 2013, 47, 14315-14323.

(24) Pace, H. E.; Rogers, N. J.; Jarolimek, C.; Coleman, V. A.; Gray, E. P.; Higgins, C. P.; Ranville, J. F. Single Particle Inductively Coupled Plasma-Mass Spectrometry: A Performance Evaluation and Method 
Comparison in the Determination of Nanoparticle Size. Environ. Sci. Technol. 2012, 46, 12272-12280.

(25) Li, L. X. Y.; Stoiber, M.; Wimmer, A.; Xu, Z. L.; Lindenblatt, C.; Helmreich, B.; Schuster, M. To What Extent Can Full-Scale Wastewater Treatment Plant Effluent Influence the Occurrence of Silver-Based Nanoparticles in Surface Waters? Environ. Sci. Technol. 2016, 50, 6327-6333.

(26) Trefry, J. C.; Monahan, J. L.; Weaver, K. M.; Meyerhoefer, A. J.; Markopolous, M. M.; Arnold, Z. S.; Wooley, D. P.; Pavel, I. E. Size Selection and Concentration of Silver Nanoparticles by Tangential Flow Ultrafiltration for SERS-Based Biosensors. J. Am. Chem. Soc. 2010, 132, 10970-10972.

(27) Yu, S. J.; Yin, Y. G.; Chao, J. B.; Shen, M. H.; Liu, J. F. Highly Dynamic PVP-Coated Silver Nanoparticles in Aquatic Environments: Chemical and Morphology Change Induced by Oxidation of $\mathrm{Ag}^{0}$ and Reduction of $\mathrm{Ag}^{+}$. Environ. Sci. Technol. 2014, 48, 403-411.

(28) Li, P.; Huang, J.; Luo, L.; Kuang, Y.; Sun, X. Universal Parameter Optimization of Density Gradient Ultracentrifugation Using CdSe Nanoparticles as Tracing Agents. Anal. Chem. 2016, 88, 8495-8501.

(29) Su, S.; Chen, B.; He, M.; Xiao, Z.; Hu, B. A Novel Strategy for Sequential Analysis of Gold Nanoparticles and Gold Ions in Water Samples by Combining Magnetic Solid Phase Extraction with Inductively Coupled Plasma Mass Spectrometry. J. Anal. At. Spectrom. 2014, 29, 444-453.

(30) Li, L.; Leopold, K. Ligand-Assisted Extraction for Separation and Preconcentration of Gold Nanoparticles from Waters. Anal. Chem. 2012, 84, 4340-4349.

(31) Zhang, L.; Chen, B.; He, M.; Liu, X.; Hu, B. Hydrophilic Polymer Monolithic Capillary Microextraction Online Coupled to ICPMS for the Determination of Carboxyl Group-Containing Gold Nanoparticles in Environmental Waters. Anal. Chem. 2015, 87, 17891796.

(32) Liu, X.; Chen, B.; Cai, Y.; He, M.; Hu, B. Size-Based Analysis of Au NPs by Online Monolithic Capillary Microextraction-ICPMS. Anal. Chem. 2017, 89, 560-564.

(33) Liu, J. F.; Chao, J. B.; Liu, R.; Tan, Z. Q.; Yin, Y. G.; Wu, Y.; Jiang, G. B. Cloud Point Extraction as an Advantageous Preconcentration Approach for Analysis of Trace Silver Nanoparticles in Environmental Waters. Anal. Chem. 2009, 81, 6496-6502.

(34) Chao, J. B.; Liu, J. F.; Yu, S. J.; Feng, Y. D.; Tan, Z. Q.; Liu, R.; Yin, Y. G. Speciation Analysis of Silver Nanoparticles and Silver Ions in Antibacterial Products and Environmental Waters via Cloud Point Extraction-Based Separation. Anal. Chem. 2011, 83, 6875-6882.

(35) Tsogas, G. Z.; Giokas, D. L.; Vlessidis, A. G. Ultratrace Determination of Silver, Gold, and Iron Oxide Nanoparticles by Micelle Mediated Preconcentration/Selective Back-Extraction Coupled with Flow Injection Chemiluminescence Detection. Anal. Chem. 2014, 86, 3484-3492.

(36) Li, L.; Leopold, K.; Schuster, M. Effective and selective extraction of noble metal nanoparticles from environmental water through a noncovalent reversible reaction on an ionic exchange resin. Chem. Commun. 2012, 48, 9165-9167.

(37) Li, L.; Hartmann, G.; Doeblinger, M.; Schuster, M. Quantification of Nanoscale Silver Particles Removal and Release from Municipal Wastewater Treatment Plants in Germany. Environ. Sci. Technol. 2013, 47, 7317-7323.

(38) Levard, C.; Hotze, E. M.; Lowry, G. V.; Brown, G. E., Jr. Environmental Transformations of Silver Nanoparticles: Impact on Stability and Toxicity. Environ. Sci. Technol. 2012, 46, 6900-6914.

(39) Mitrano, D. M.; Lesher, E. K.; Bednar, A.; Monserud, J.; Higgins, C. P.; Ranville, J. F. Detecting Nanoparticulate Silver Using Single-Particle Inductively Coupled Plasma-Mass Spectrometry. Environ. Toxicol. Chem. 2012, 31, 115-121.

(40) Yang, Y.; Long, C. L.; Li, H. P.; Wang, Q.; Yang, Z. G. Analysis of Silver and Gold Nanoparticles in Environmental Water Using Single Particle-Inductively Coupled Plasma-Mass Spectrometry. Sci. Total Environ. 2016, 563-564, 996-1007.
(41) Mahbubul, I. M.; Saidur, R.; Amalina, M. A.; Elcioglu, E. B.; Okutucu-Ozyurt, T. Effective Ultrasonication Process for Better Colloidal Dispersion of Nanofluid. Ultrason. Sonochem. 2015, 26, 361-369.

(42) Tso, C. P.; Shih, Y. H. The Reactivity of Well-Dispersed Zerovalent Iron Nanoparticles toward Pentachlorophenol in Water. Water Res. 2015, 72, 372-380.

(43) Shen, M. H.; Yin, Y. G.; Booth, A.; Liu, J. F. Effects of Molecular Weight-Dependent Physicochemical Heterogeneity of Natural Organic Matter on the Aggregation of Fullerene Nanoparticles in Mono- and Di-valent Electrolyte Solutions. Water Res. 2015, 71, 11-20.

(44) Pokhrel, L. R.; Dubey, B.; Scheuerman, P. R. Impacts of Select Organic Ligands on the Colloidal Stability, Dissolution Dynamics, and Toxicity of Silver Nanoparticles. Environ. Sci. Technol. 2013, 47, 12877-12885.

(45) Zhou, X. X.; Liu, J. F.; Yuan, C. G.; Chen, Y. S. Speciation Analysis of Silver Sulfide Nanoparticles in Environmental Waters by Magnetic Solid-Phase Extraction Coupled with ICP-MS. J. Anal. At. Spectrom. 2016, 31, 2285-2292.

(46) Jin, X.; Li, M.; Wang, J.; Marambio-Jones, C.; Peng, F.; Huang, X.; Damoiseaux, R.; Hoek, E. M. V. High-Throughput Screening of Silver Nanoparticle Stability and Bacterial Inactivation in Aquatic Media: Influence of Specific Ions. Environ. Sci. Technol. 2010, 44, $7321-7328$.

(47) Mueller, N. C.; Nowack, B. Exposure modeling of engineered nanoparticles in the environment. Environ. Sci. Technol. 2008, 42, $4447-4453$

(48) Gottschalk, F.; Sun, T.; Nowack, B. Environmental concentrations of engineered nanomaterials: Review of modeling and analytical studies. Environ. Pollut. 2013, 181, 287-300.

(49) Sun, T. Y.; Gottschalk, F.; Hungerbuehler, K.; Nowack, B. Comprehensive probabilistic modelling of environmental emissions of engineered nanomaterials. Environ. Pollut. 2014, 185, 69-76.

(50) Sun, T. Y.; Bornhoft, N. A.; Hungerbuhler, K.; Nowack, B. Dynamic Probabilistic Modeling of Environmental Emissions of Engineered Nanomaterials. Environ. Sci. Technol. 2016, 50, 47014711. 